\title{
ROAD TRAFFIC INJURIES IN SAUDI ARABIA, AND THEIR IMPACT ON THE WORKING POPULATION
}

\author{
By \\ Elshinnawey M.*, Fiala L.*, Abbas M.*, Othman N.** \\ From \\ *Dept of Community and Occupational Medicine, Suez Canal University, Egypt \\ ** Dept. of Statistics, Ministry of Health, Saudi Arabia
}

\begin{abstract}
:
This study aimed at describing the problem of Road Traffic Injuries (RTIs) in Saudi Arabia and their impact on the working population in terms of reduced productivity. Data on road traffic injuries and deaths were collected for the period of 1997 to 2002 and compared to population census during the same period. Potential Productive Years of Life Lost (PPYLL) was calculated. The total number of deaths due to RTIs was 21905 deaths and the total PPYLL due to RTIs was 459820.81. In all age groups, the losses in males were 1.91 to 8.52 times greater than in females, the differences were statistically significant. Both males and females showed an increasing trend of PPYLL for 20 - 29 years, 30 - 39 years, and $10-19$ years old age groups. The increasing trend was more impressive in males. PPYLL average was 50000 years annually in the productive years of life in years 1997 to 2002, with about $33 \%$ increase in 2002. RTIs are a major health problem affecting all age groups; working population are more vulnerable due to commuting. Losses in productive years are more prominent and serious in productive age groups.
\end{abstract}




\section{Introduction}

Between 1971 and 1997, 564,762 people died or were injured in Road Traffic accidents, a figure equivalent to $3.5 \%$ of the total population in The Kingdom of Saudi Arabia (KSA). During this period, 66,914 people have died on the roads in KSA due to RTIs amounting to one person killed and four injured every hour ${ }^{(1)}$. An audit of RTIs over one-year period revealed that, out of 361 victims, $16 \%$ were less than 10 years and $47 \%$ were between 11 and 30 years, indicating a high productivity loss ${ }^{(2)}$.

Despite the importance of injury as a public health problem in KSA, few studies were concerned with economic and social impact. This is due to many factors most of them are related to availability of reliable data ${ }^{(3)}$.

The lack of official and comprehensive information about this issue, particularly regarding morbidity and retirement due to disability/invalidism consequent on road traffic injury, impairs the measurement of its economic and social impact. That is why studies based on mortality are the most feasible.

Knowing about the productive years of life lost due to premature death provides important information to the health sector and social security. It partially reflects the social impact of the problem, whose prevention and/or control were unquestionably beneficial ${ }^{(4)}$.
The concept of potentially productive years of life lost (PPYLL) is based on the productive value of individuals ${ }^{(5)}$. This value of human life goes back for many years. In 1982, the US Center for Disease Control introduced the concept of years of potential life lost (YPLL) $(0-64)$. Years of Productive Life Lost (YPLL) have been used by the Pan American Health Organization ${ }^{(6}$ and 7$)$.

The World Health Organization has developed a complex method for estimating disability adjusted years of life lost, or DALYs, based in part on the assumption that every one should have the life expectancy of Japanese females due to their extended years of longevity ${ }^{(8)}$. While DALYs measure the potential impact of health problem on the quality of life of the individuals, PPYLL provide more relevant information about the effect of a medical condition on the economy.

The measure, PPYLL (age 15-65), also underscores the importance of productivity as a vital part of a country's development. We chose this method in preference to PYLL, which include the years lost well beyond the productive years ${ }^{(9)}$.

The present study aimed at estimating the number of Potential Productive Years of Life Lost (PPYLL) due to Road Traffic injuries in KSA and reporting their trend in 6 years period $(1997-2002)$. 


\section{Methods}

\section{Source of data:}

Data were collected from the registry of the official mortality reports of The Ministry of Health of KSA. The cause of death was recorded as "road traffic accident" and deaths were grouped under the codes from V1 to V99 of the International Classification of Diseases, $10^{\text {th }}$ revision. The population figures for the years 1997 to 2002 were obtained from the General Statistics Authority of KSA for calculating the mortality rates due to Road Traffic Injuries in 2 temporal points (1997 and 2002).

\section{Data management and analysis:}

Data were imported from the computer department to SPSS version 11. The data were revised for completeness and consistency. Any incomplete or inconsistent data were subjected to a comparison to its reference records of mortality files for correction. These files came from the different health regions of KSA to be dealt with and coded according to WHO basis. Cases of RTIs were selected in a separate SPSS data file.

The analysis was descriptive with the raw frequencies of the productive years of life lost. Methods of least square were adopted to measure the trend of frequencies of potential productive years of life lost (PPYLL) due to Road Traffic
Injuries. Means, standard deviations, intergroup (males \& females) and intra-group (age groups) means were calculated for the PPYLL. The percentages of increase or reduction in the number of deaths in the covered period in the study were also calculated. Chi Square test was used for qualitative data while t test was used for quantitative data.

\section{Calculation of productive years of life lost:}

The productive years of life lost method assumes that the working age span can be changed from country to another. In this study, it was considered to be between 15 - 60 years. For deaths before age 15, it is assumed that if the children have survived, they would have worked the full 45 years ( 15 $-60)$. To calculate the productive years of life lost, the equation that is used to calculate the potential years of life lost (10 and 11), was modified to be limited to the productive age $(15-60)$. From the economic aspect, a discount rate of $3 \%$ was used to represent the actual productivity. This is based on the economic principle that assumes that the years in the future are worth less than years in the present. The World Bank and WHO also used a $3 \%$ discount rate ${ }^{(12)}$.

\section{Results}

From table 1, during the studied 6 years (1997 - 2002), the total number of deaths that was defined among $20-60$ years age group due to RTAs was 15882 deaths. Male 
deaths constituted $87.7 \%$ (13931 deaths). Male deaths per year due to RTAs ranged from 1987 deaths (1998) to 3005 deaths (2002). Female deaths per year due to RTAs ranged from 303 deaths (1998) to 376 deaths (2002) During the same period, the total potential productive years of life lost (PPYLL) due to RTAs were 304941.86. The total loss in males constituted $88.24 \%$ of the PPYLL. Males' loss per year ranged from 37672.45 in 1998 to 58672.96 in 2002 PPYLL. Females' loss per year ranged from 5513.67 in 1998 to 6952.48 in 2002 PPYLL.

Table (2) shows that the mean age at death in males was significantly higher than that of females $(\mathrm{P}<0.05)$. In males, the mean age at death ranged from 28.3 (2000) to 29.0 years (1999). In females, the mean age at death ranged from 23.2 (1998) to 25.2 years $(2002)$.

Table 3 shows the annual mean and ratios of the PPYLL due to RTIs. For males, the annual mean loss was 64605.33 PPYLL which is 5.37 times that of females, for whom the annual mean loss was 12031.48. The difference between males and females loss was statistically highly significant $(\mathrm{P}$ $<0.001)$. In all age groups, the losses in males were 2.03 to 8.52 times greater than in females. The differences between males and females loss in all age groups were statistically highly significant $(\mathrm{P}<0.0001)$ except for the 0-9 age group deaths $(\mathrm{P}<$ 0.05). Concerning the intra-group mean ratios, it is observed that the ratio between the mean of PPYLL for each age group and that immediately above it in males was not practically different from that of females.

The percentages of increase or decrease in the number of deaths due to Road Traffic Injuries in the year 2002 compared to year 1997 are presented in table 4. A 31.63\% increase was observed for males compared to $1.31 \%$ for females. For males, the percentages ranged from $-2.80 \%$ for the age group $0-9$ years to $56.52 \%$ for the age group $20-29$ years, while they ranged from $-20.00 \%$ for the age group $0-9$ years to $40.45 \%$ for 20 - 29 age group in females indicating to a higher loss in males than females and in productive age groups than nonproductive's .

In table 5 , the percentage of increase in female population (8.67\%) was higher than that of male population ( $8.53 \%$ ) while the percentage of increase of male deaths $(31.63 \%)$ was higher than that of female deaths.

The rate of annual change of PPYLL due to RTIs in the period from 1997 to 2002 was presented in figure 1 . The annual rate of increase in males was 3799.6 PPYLL/ year. For females it was decreasing by -30.1 PPYLL/year 


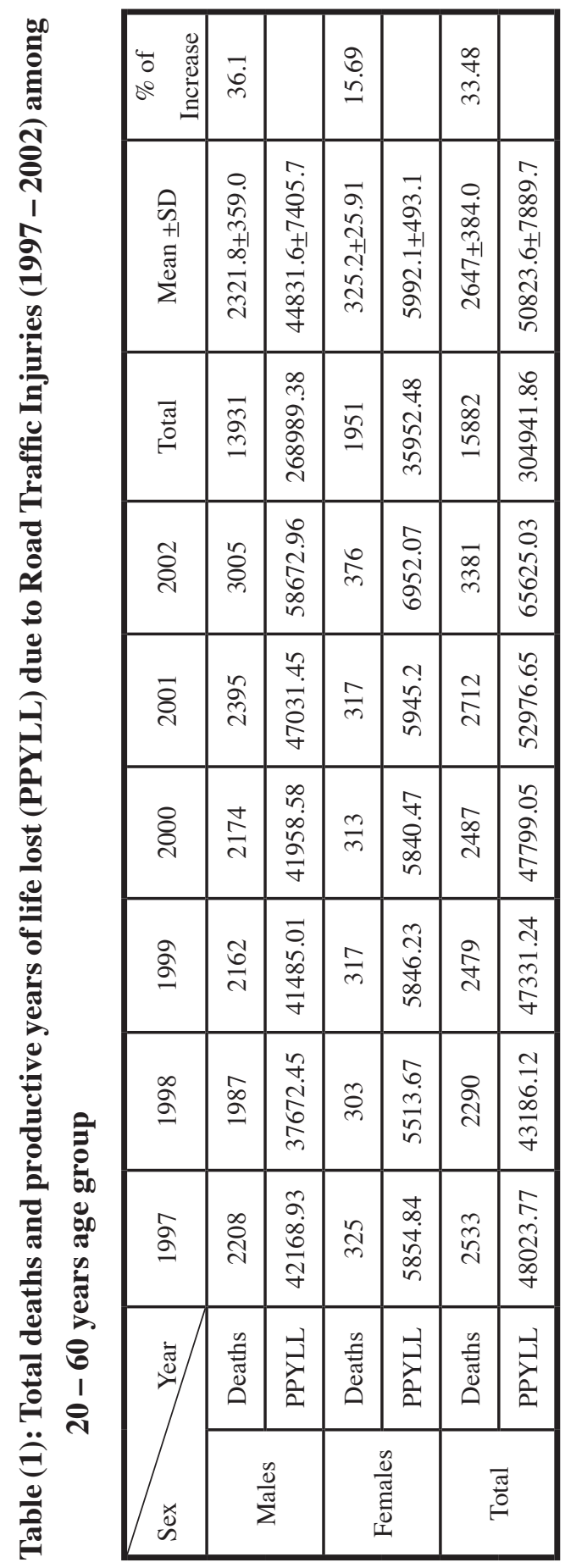


Table (2): Mean and standard deviation (std. dev.) of age at time of death due to Road Traffic Injuries in the 0 to 60 age group for male and female in Saudi Arabia 1997 - 2002

\begin{tabular}{|c|c|c|c|}
\hline \multirow{2}{*}{ Sex Year } & Male. & Female & All \\
\cline { 2 - 4 } & Mean \pm S.D. & Mean \pm S.D. & Mean \pm S.D. \\
\hline $1997^{*}$ & $28.6 \pm 14.3$ & $23.2 \pm 17.4$ & $27.7 \pm 15.0$ \\
\hline $1998^{*}$ & $28.8 \pm 14.2$ & $23.2 \pm 17.5$ & $27.9 \pm 15.0$ \\
\hline $1999^{*}$ & $29.0 \pm 13.8$ & $24.9 \pm 16.8$ & $28.4 \pm 14.4$ \\
\hline $2000^{*}$ & $28.3 \pm 13.9$ & $25.0 \pm 16.4$ & $27.8 \pm 14.4$ \\
\hline $2001^{*}$ & $28.5 \pm 13.2$ & $24.1 \pm 16.5$ & $27.9 \pm 13.8$ \\
\hline $2002 *$ & $28.9 \pm 13.2$ & $25.2 \pm 16.5$ & $28.4 \pm 13.7$ \\
\hline Total $^{*}$ & $28.7 \pm 13.7$ & $24.3 \pm 16.9$ & $28.0 \pm 14.3$ \\
\hline
\end{tabular}

*The mean ages at death in males were significantly higher than females $(\mathrm{p}<0.05)$

Table (3): Annual mean, standard deviation (std. dev.) of years of life lost due to Road Traffic Injuries in Saudi Arabia 1997 - 2002 by age.

\begin{tabular}{|c|c|c|c|c|c|}
\hline \multirow{2}{*}{ AGE GROUP } & \multicolumn{2}{|c|}{ MALE } & \multicolumn{2}{|c|}{ FEMALE } & \multirow{2}{*}{$\begin{array}{c}\text { MALE/ } \\
\text { FEMALE } \\
\text { RATIO }\end{array}$} \\
\hline & Mean & Std. dev. & Mean & Std. dev. & \\
\hline $0-9^{*}$ & 7915.44 & 486.30 & 3897.30 & 624.45 & 2.03 \\
\hline $10-19 * *$ & 11279.99 & 1810.32 & 1839.98 & 356.91 & 6.13 \\
\hline $20-29 * *$ & 18553.51 & 4264.80 & 2177.58 & 377.19 & 8.52 \\
\hline $30-39 * *$ & 15889.32 & 2083.92 & 2079.84 & 166.10 & 7.64 \\
\hline $40-49 * *$ & 7829.47 & 983.80 & 1137.14 & 80.09 & 6.89 \\
\hline $50-60 * *$ & 2559.26 & 285.88 & 597.53 & 118.81 & 4.28 \\
\hline Total* & 64605.33 & 9143.45 & 12031.48 & 985.79 & 5.37 \\
\hline
\end{tabular}

$* \mathrm{P}<0.05 \quad * * \mathrm{P}<0.0001$ 
Table (4): Percentage of increase or decrease in the number of deaths due to Road Traffic Injuries in Saudi Arabia during the period 1997 - 2002 by age

\begin{tabular}{|c|c|c|}
\hline \multirow{2}{*}{ Indicator } & \multicolumn{2}{|c|}{ (\%) of } \\
& & \multicolumn{2}{|c|}{ Increase or decrease } \\
\cline { 2 - 4 } Age group & Males & Females \\
\hline $0-9$ & -2.80 & -20.00 \\
\hline $10-19$ & 41.56 & -2.22 \\
\hline $20-29$ & 56.52 & 40.45 \\
\hline $30-39$ & 27.40 & 4.21 \\
\hline $40-49$ & 34.58 & 5.48 \\
\hline $50-60$ & 10.79 & 10.29 \\
\hline Total & 31.63 & 1.31 \\
\hline
\end{tabular}

Table (5): Population census, deaths, and mortality rates due to Road Traffic Injuries in two points of 1997 and 2002

\begin{tabular}{|c|c|c|c|c|c|c|c|c|c|}
\hline \multirow[b]{2}{*}{ 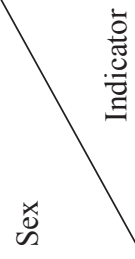 } & \multicolumn{3}{|c|}{ Total Population } & \multicolumn{3}{|c|}{ Deaths } & \multicolumn{3}{|c|}{ Deaths/100000 population } \\
\hline & 1997 & 2002 & $\begin{array}{c}(\%) \text { of } \\
\text { Increase } \\
\text { or } \\
\text { Reduction }\end{array}$ & 1997 & 2002 & $\begin{array}{c}(\%) \text { of } \\
\text { Increase } \\
\text { or } \\
\text { Reduction }\end{array}$ & 1997 & 2002 & $\begin{array}{c}(\%) \text { of } \\
\text { Increase } \\
\text { or } \\
\text { Reduction }\end{array}$ \\
\hline Males & 10425822 & 11314966 & 8.53 & 2975 & 3916 & 31.63 & 28.53 & 34.61 & 21.29 \\
\hline Females & 8771043 & 9531918 & 8.67 & 611 & 619 & 1.31 & 6.97 & 6.49 & -6.78 \\
\hline
\end{tabular}




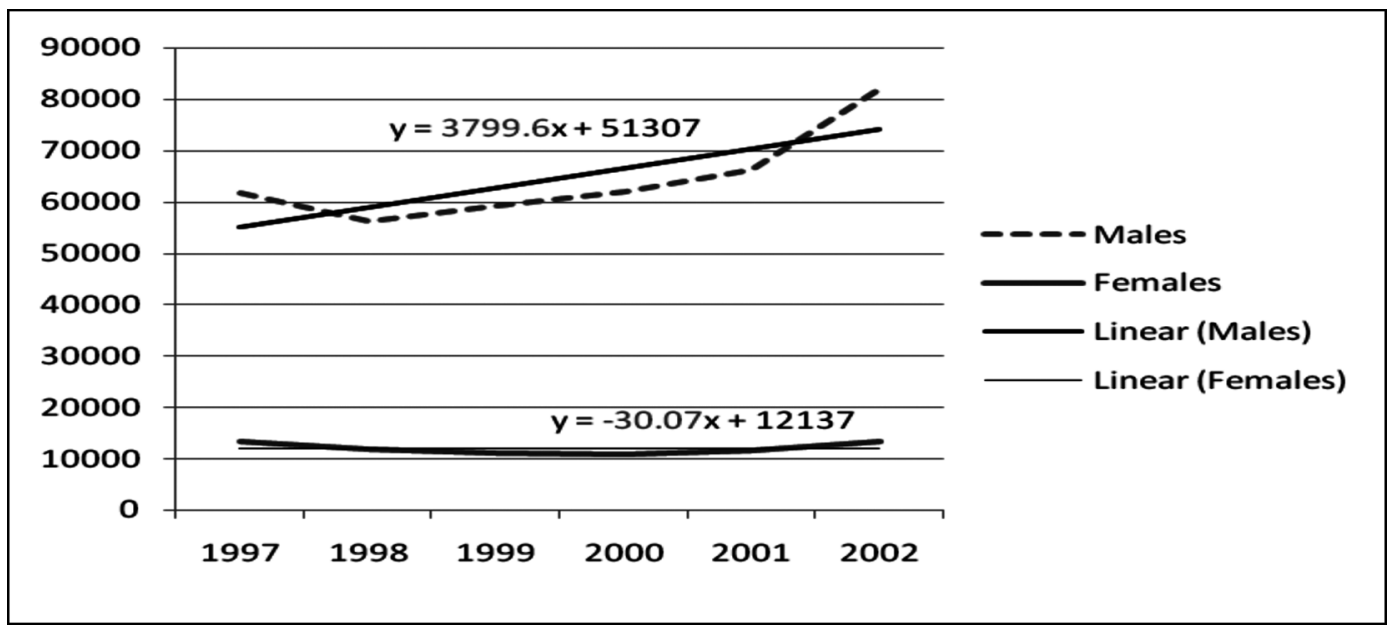

Figure (1): Trend of PPYLL in males and females in the period between $1997-2002$ G.

\section{Discussion}

KSA is one of the developing and industrializing countries, so it is very essential to decrease disease and injury losses for the productive working population. With rapid expansion of road construction and increase in the number of vehicles, RTIs are becoming a serious public health problem ${ }^{(13)}$. One of the ways of evaluation of this problem is the determination of PPYLL which reflects the productivity losses. This study aimed at estimating the number of PPYLL due to RTIs in KSA and reporting their trend in 6 years period.

In the studied 6 years $(1997-2002)$, there was an increase in the number of deaths due to RTIs during economically productive years for both sexes. The percentage of increase was more impressive in males $(31.63 \%)$ than females $(1.31 \%)$. Previous studies in KSA found a higher percentage of increase (20 times higher than the current study) ${ }^{(14)}$. In comparison to European countries (Greece) the general rate of increase was $32 \%{ }^{(14,15)}$.

The annual mean of PPYLL due to RTIs was significantly higher for males than for females. The available literature was mainly directed to study the sex role in RTIs' fatalities rather than PPYLL. Few studies (16-18) considered the value of PPYLL due to RTIs and its association with gender. The highest ratio between males and females in these studies was less than that detected in the current study. The highest ratio in the current study was detected for the $20-29$ and 30 - 39 age groups indicating a higher 
loss in productive years of males, being in concordance with some studies ${ }^{(2,16 \text { and 19). }}$

The current study detected an increasing rate of annual change (trend) of PPYLL due to RTIs in the period from 1997 to 2002. The annual rate of increase in males was 3799.6 PPYLL/year. The annual trend for females was decreasing by -30.1 PPYLL/ year. These figures were not in accordance with those of Jakuboniene and Gurevicius ${ }^{(20)}$, who studied the sex role in mortality due to RTIs. They found a decrease of mortality due to RTIs for male and female sex but the decrease was highly expressed in females. In the gulf area, ${ }^{(21)}$ an overall decrease in RTIs fatality by a trend of (-1.10) was detected.

The trend of PPYLL in the different age groups differs according to age groups. Both males and females showed an increasing trend of PPYLL for 20 - 29,30 - 39, and 10 - 19 years age groups in descending order. The increasing trend was more impressive in males. These findings are supported by many studies (16-17, 22-23). Only one study in Belgium found a decreasing trend in PPYLL (24).

In conclusion, the study revealed an increase in the number of deaths due to RTIs in the economically active age groups for both sexes. The increase was more impressive in males. Parallel to this increase, an increasing trend in the PPYLL was detected. Decision makers interested in the nation's productivity should adopt a program for health education and prevention of RTIs.

\section{References}

1. Ansari S, Akhdar F, Mandoorah M and Moutaery $\mathrm{K}$ : Causes and effects of Road Traffic Injuries in Saudi Arabia. Public Health; 2000; 114 (1): 37 9.

2. Shanks NJ, Ansari M, and Al-Kalali D: Road Traffic Injuries in Saudi Arabia. Public Health; 1994; 108 (1): 27 - 34.

3. Bener A and Jadaan KS: A prospective on road traffic fatalities in Jeddah, Saudi Arabia. Accid Analy \& Prevent. 1992; 24 (2): 143 - 8.

4. Lolio CA, Lotufo PA, Lira AC, Zanetta DM and Massad E: Trend of mortality due to ischemic heart disease of the capital of Metropolitan region in Brazil. Arq Bras Cardiol; 1995; 64: 195 - 9.

5. Zhou Y, Baker TD, Rao K, and Li G: Productivity losses from injury in China. Inj Prevent; 2003; 9: $124-7$.

6. CDC: Introduction to table V. Premature deaths, Maternal mortality etc, Atlanta, GA. United States. 1982; 31: 109 10, 17.

7. Pan American Health Organization: Health conditions in the Americas. Volume 1. Scientific Publication No 500. Washington, DC: PAHO; 1986: $369-90$. 
8. Murray CJL and Lopez AD: The global burden of disease. Cambridge, MA. Harvard Univ Press; 1996: PP. $553-6$.

9. Ministry of Health, People's Republic of China: Research on National Health Services - an analysis report of the Second National Health Services Survey in 1998. Beijing: National Centre for Health information and statistics, 1999.Ch. 1.

10. Mathers C, Vos T and Stevenson C: The burden of disease and injury in Australia. Australian Institute of Health and Welfare. Canberra: AIHW 1999: p1-10.

11. Gardener JW and Sanborn JS. Y: Years of potential life lost-what does it measure? Epidemiol; 1990:1: 322- 9 .

12. World Bank. World development report: Invest in health. New York: Oxford Univ Press; 1993: PP. 26.

13. Ofosu JB, Abouammoh AM and Bener A: A study of Road Traffic Injuries in Saudi Arabia. Accid Anal prev; 1988:20 (2): 95 - 101.

14. Ergun G: Conditions of vehicles in Saudi Arabia. Accid Anal prev; 1987; 19 (5): 343 - 58.

15. Kardara M and Kondakis X: Road Traffic Injuries in Greece: recent trends (1981 - 1991). Eur J Epidemiol; 1997; 13 (7): 765 - 70.

16. Chi GB and Wang SY: A comparative study on mortality and YPLL of accidents. Zhonghuali Xing Bing Xue Za Zhi; 1996; 17 (4): 195 - 8.
17. Emmanuel S: Epidemiology of injuries in Singapore. Ann Acad Med Singapore; 1991;20 (2): $190-5$

18. Duma O: Road accidents morbidity and mortality in district of Vrancea. Rev Med Chir Soc Med Nat Lasi; 2002; 106 (4): 787 - 91.

19. Wang SY, Chi GB, Jing CX, Dong XM, Wu CP and Li LP: Trends in road traffic crashes and associated injury and fatality in the People's Republic of China, 1951 - 1999. Inj Control Saf Promot; 2003; 10 (1-2): 83 - 7.

20. Jakuboniene D and Gurevicius R,: Mortality from external causes: influence of age and gender. Medicina (Kaunas); 2003; 39 (8): 773 - 87.

21. El-Sadig M, Norman JN, Lioyd OL, Romilly P and Bener A: Road Traffic Injuries in the United Arab Emirates: trends of morbidity and mortality during 1977 - 1998. Accid Anal Prev; 2002; 34 (4): $465-76$.

22. Langley JD and Mcloughlin E: Injury mortality and morbidity in New Zealand. Accid Anal Prev; 1989; 21 (3): $243-54$.

23. Montazeri A: Road traffic-related mortality in Iran: a descriptive study. Public health; 2004; 118 (2): $110-3$.

24. Leveque A, Humblet PC and Lagasse R: Premature avoidable deaths by road traffic injuries in Belgium: trends and geographical disparities. Eur J Epidemiol; 2001; 17 (9): 841 5. 